\title{
Mechanical Stabilization of Deoxyribonucleic Acid Solid Films Based on Hydrated Ionic Liquid
}

Yuma Morimitsu, ${ }^{\dagger}$ Hisao Matsuno,,,,,$+++ \#$ Noboru Ohta,${ }^{\S}$ Hiroshi Sekiguchi, ${ }^{\S}$ Atsushi Takahara $,{ }^{l}, \#$ and Keiji Tanaka $*,+,+, \#$

Department of Applied Chemistry, Kyushu University, Fukuoka 819-0395, Japan

International Institute for Carbon-Neutral Energy Research (WPI-I2CNER), Kyushu University, Fukuoka 819-0395, Japan

§Japan Synchrotron Radiation Research Institute (JASRI), Hyogo 679-5198, Japan

"Institute for Materials Chemistry and Engineering, Kyushu University, Fukuoka 819-0395, Japan

${ }^{\#}$ Center for Polymer Interface and Molecular Adhesion Science, Kyushu University, Fukuoka 8190395, Japan

*To whom correspondence should be addressed

FAX: $+81-92-802-2880 \quad$ TEL: $+81-92-802-2878$

E-mail: h-matsuno@cstf.kyushu-u.ac.jp (H.M.) \& k-tanaka@cstf.kyushu-u.ac.jp (K.T.) 


\section{EXPERIMENTAL}

1.1 Sample Preparation for Tensile Tests. Figure S1 shows a typical photograph for a solid film of deoxyribonucleic acid (DNA) containing choline dihydrogen phosphate (CDP), named DC film, with a dumbbell shape used for tensile tests.

(a)

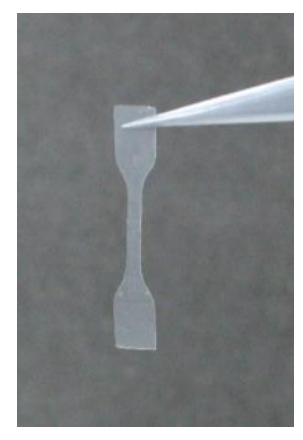

(b)

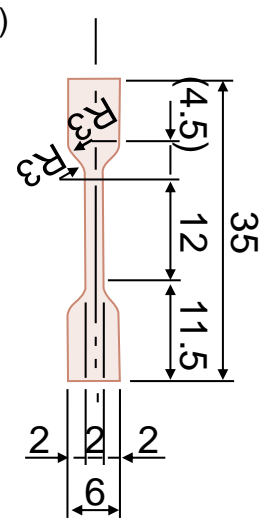

Figure S1. (a) A test piece of a DC film with a dumbbell shape. (b) Size of the piece in millimeter units.

\section{RESULTS AND DISCUSSION}

2.1. Chemical Composition. Figure $\mathrm{S} 2$ shows the chemical composition of DC10, DC20, DC25, and DC30 films. The water content in the films was relatively lower than that in the films after the wet treatment, and was almost $\sim 15 \mathrm{wt} \%$, regardless of the feed ratio of CDP. DC40 and DC50 films were also prepared. Unfortunately, moisture was easily adsorbed to these films under ambient conditions, leading to difficulty in accurately evaluating the chemical composition. Thus, these films were not further examined.

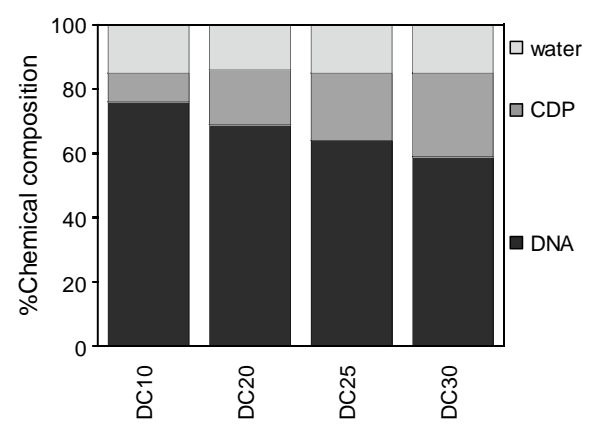

Figure S2. Chemical composition for DC films determined by thermogravimetry.

2.2. Interaction between DNA and CDP. Panel (a) of Figure S3 shows attenuated total reflection Fourier transform infrared (ATR FT-IR) spectra for DNA-w and DC films. As a reference, a FT-IR spectrum for a $\mathrm{CDP} / \mathrm{D}_{2} \mathrm{O}$ solution acquired at transmittance mode is also shown. In the spectrum for the DNA-w film, three peaks and two shoulders were observed. Peaks at (I) 1,222, (III) 1,054 , and (V) $959 \mathrm{~cm}^{-1}$ for the DNA-w film were assigned to the antisymmetric stretching vibration of $\mathrm{PO}_{2}{ }^{-}$, the symmetric stretching vibration of $\mathrm{C}-\mathrm{O}$ at deoxyribose-ring, and the stretching vibration of the backbone (C4'-C5' of deoxyribose-ring), respectively. ${ }^{\text {S1 }}$ Shoulders at (II) 1,080 and (IV) 1,013 $\mathrm{cm}^{-1}$ were attributed to the symmetric stretching vibration of $\mathrm{PO}_{2}{ }^{-}$and the deoxyribose-ring vibration, respectively. ${ }^{\mathrm{S} 1}$ In the spectrum for the $\mathrm{CDP} / \mathrm{D}_{2} \mathrm{O}$ solution, two peaks and three shoulders were observed. Peaks at (i) 1,163 and (ii) $1,076 \mathrm{~cm}^{-1}$ were assigned to the $\mathrm{CH}_{2}$ bending near $\mathrm{OH}$ and the 
$v_{4}$ mode of $\mathrm{HPO}_{4}{ }^{2-}$, respectively. ${ }^{\mathrm{S} 2 \mathrm{~S} 3}$ Shoulders at (iii) 952, (iv) 930, and (v) $862 \mathrm{~cm}^{-1}$ were attributed to the $\mathrm{C}-\mathrm{N}$ antisymmetric and symmetric stretching vibrations, and the $\mathrm{PO}_{4}{ }^{3-}$ stretching vibration, respectively. ${ }^{\mathrm{S} 2, \mathrm{~S} 3}$

The wavenumber regions around the shoulder (II) and the peak (V) of DNA were overlapped with ones around the peak (ii) and the shoulder (iii) of CDP. Thus, these two peaks (II and V) from DNA were excluded from the discussion. While the peak (I) and shoulder (IV) positions were independent of the CDP amount in the film, the peak (III) clearly shifted to a lower wavenumber side with increasing CDP amount, as shown in Figure 3(b). These results imply that hydrogen bonds form between deoxyribose-ring and CDP. Unfortunately, any peaks attributed to the vibration mode of proton-donor groups such as $\mathrm{OH}$ and $\mathrm{CH}$ of choline could not be differently detected because these functional groups also existed in DNA and $\mathrm{H}_{2} \mathrm{O}$ (data not shown). However, taking into account that choline localized near the base pair or the sugar-ring of DNA, ${ }^{\mathrm{S} 4 \mathrm{~S} 5}$ the shift of the peak (III) makes it clear that the formation of hydrogen bonds between $\mathrm{C}-\mathrm{O}$ of deoxyribose-rings of DNA and $\mathrm{OH}$ and/or $\mathrm{CH}$ of choline of CDP.
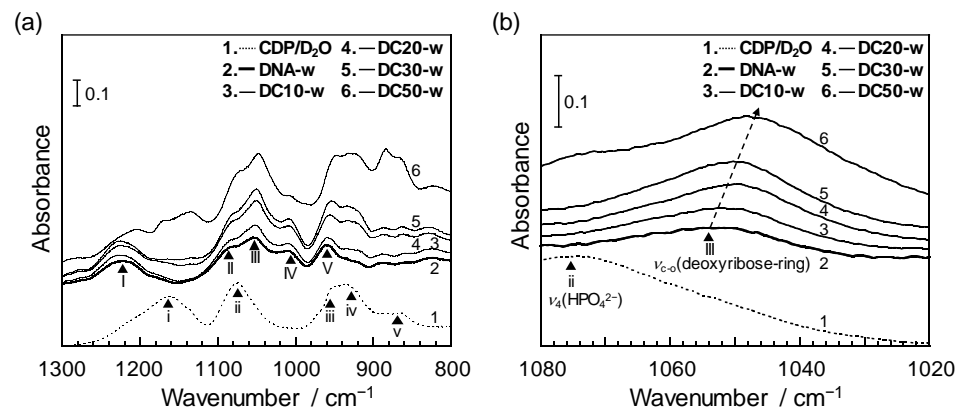

Figure S3. (a) ATR FT-IR spectra for DNA-w and DC films and a FT-IR spectrum for a CDP/D $2 \mathrm{O}$ solution at $5 \mathrm{~mol} \cdot \mathrm{l}^{-1}$. Peaks at (I) 1,222 , (III) 1,054 , and (V) $959 \mathrm{~cm}^{-1}$ for the DNA-w film were assigned to the antisymmetric stretching vibration of $\mathrm{PO}_{2}^{-}$, the symmetric stretching vibration of $\mathrm{C}-\mathrm{O}$ at deoxyribose-ring, and the stretching vibration of the backbone (C4'-C5' of deoxyribose-ring), respectively. Shoulders at (II) 1,080 and (IV) $1,013 \mathrm{~cm}^{-1}$ for the DNA-w film were attributed to the symmetric stretching vibration of $\mathrm{PO}_{2}^{-}$ and the deoxyribose-ring vibration, respectively. Peaks at (i) 1,163 and (ii) $1,076 \mathrm{~cm}^{-1}$ for the $\mathrm{CDP} / \mathrm{D}_{2} \mathrm{O}$ solution were assignable to the $\mathrm{CH}_{2}$ bending vibration near $\mathrm{OH}$ and the $v_{4}$ mode of $\mathrm{HPO}_{4}{ }^{2-}$ of $\mathrm{CDP}$, respectively. Shoulders at (iii) 952 , (iv) 930 , and (v) $862 \mathrm{~cm}^{-1}$ for the $\mathrm{CDP} / \mathrm{D}_{2} \mathrm{O}$ solution were assigned to the $\mathrm{C}-\mathrm{N}$ antisymmetric and symmetric stretching vibrations, and the $\mathrm{PO}_{4}{ }^{3-}$ stretching of $\mathrm{CDP}$, respectively. (b) Enlarged spectra of (a) ranging from 1,020 to $1,080 \mathrm{~cm}^{-1}$.

2.3. Denaturation of DNA. Panel (a) of Figure S4 shows temperature-dependent ultraviolet (UV) absorption spectra for (a) a DC10-w film and (b) a DNA/CDP aqueous solution, respectively. While the spectrum shape for the film remained unchanged in the temperature range up to $423 \mathrm{~K}$, it started to change around $320 \mathrm{~K}$ in the solution. That is, dsDNA was not transformed to ssDNA in the film, unlike in the solution state.
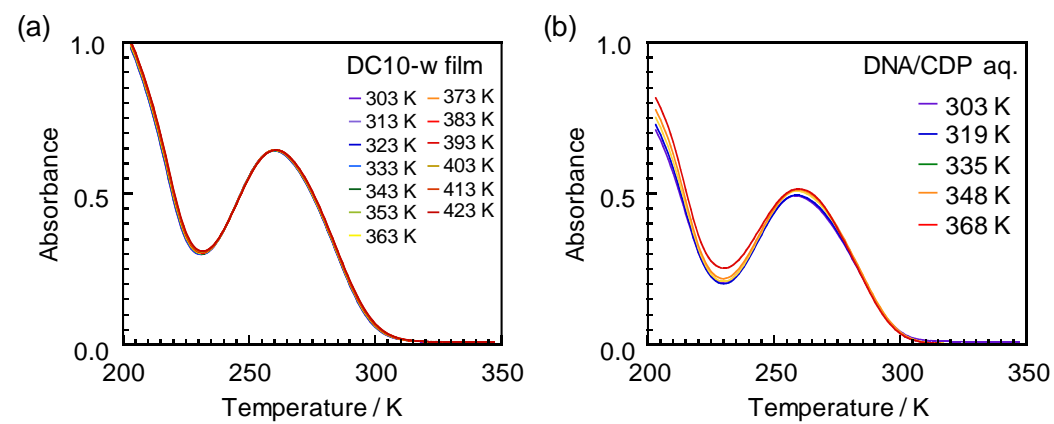

Figure S4. Temperature-dependent UV spectra in the heating process for (a) a DC10-w film and (b) a DNA/CDP aqueous solution with the ratio of DNA/CDP (90/10 (wt/wt)). 
2.4. Thermal Molecular Motion. Panel (a) of Figure S5 shows the relationship between $\ln f$ and the reciprocal $T$, where $f$ and $T$ are frequency and absolute temperature, respectively, for the $\beta$ relaxation peaks of the DC films. Panel (b) of Figure S5 shows apparent activation energy for the $\beta$ process $\left(\Delta H^{*} \beta\right)$ as a function of CDP content. Panel (c) of Figure S5 shows the $\beta$-relaxation temperature $\left(T_{\beta}\right)$ at $f=3.5 \mathrm{~Hz}$ as a function of the $\mathrm{CDP}$ content.
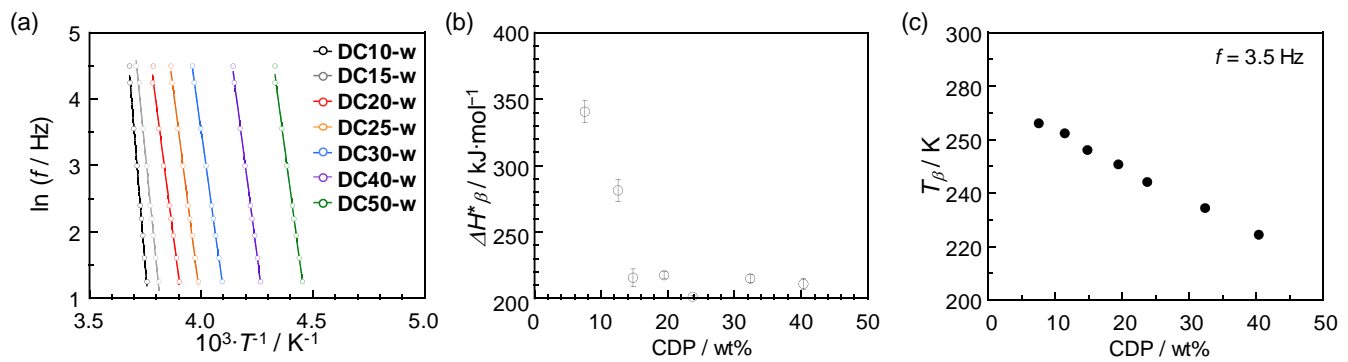

Figure S5. (a) Relationships between $\ln f$ and $T^{-1}$ for the $\beta$-relaxation process of DC films; (black) DC10w, (gray) DC15-w, (red) DC20-w, (orange) DC25-w, (blue) DC30-w, (purple) DC40-w, and (green) DC50$\mathrm{w}$ films. (b) CDP fraction dependence on activation energy for the $\beta$-relaxation process $\left(\Delta H^{*} \beta\right)$. (c) CDP fraction dependence on $\beta$-relaxation temperature acquired at $f$ of $3.5 \mathrm{~Hz}$.

2.5. Tensile properties. Figure $S 6$ shows stress-strain $(S-S)$ curves for the DC10, DC20, DC25, and DC30 films. For all films, a steep rise accompanying a yield point was observed at a strain $(\varepsilon)$ of approximately 0.1 . The DC10 film having the lowest CDP content showed the highest Young's modulus of approximately 1.0 GPa. This value was slightly lower than that for the neat DNA film ( $1.7 \mathrm{GPa}$ ) without CDP. ${ }^{\mathrm{S} 6}$ When the CDP content increased in the film, the Young's modulus decreased to approximately $380 \mathrm{MPa}$. While the yield strain was almost independent of the CDP content, the yield stress decreased with increasing CDP content. The breaking point increased as the CDP content increased. However, the greatest $\varepsilon$, where the break occurred, was at most approximately 0.4 , indicating that more water molecules were required to make the film rubbery.



Figure S6. Stress-strain (S-S) curves for non-wet treated DC films with lower water contents. The measurements were performed at room temperature with a crosshead speed of $10 \mathrm{~mm} \cdot \mathrm{min}^{-1}$.

Table S1. Parameters regarding tensile properties of non-wet treated DC films.

\begin{tabular}{ccccccc}
\hline Films & $\begin{array}{c}\text { Young's modulus } \\
(\mathrm{MPa})\end{array}$ & $\begin{array}{c}\text { yield point } \\
(-)\end{array}$ & $\begin{array}{c}\text { yield stress } \\
(\mathrm{MPa})\end{array}$ & $\begin{array}{c}\text { breaking point } \\
(-)\end{array}$ & $\begin{array}{c}\text { breaking stress } \\
(\mathrm{MPa})\end{array}$ & $\begin{array}{c}\text { toughness } \\
(\mathrm{MPa})\end{array}$ \\
\hline DC10 & $1010 \pm 70$ & $0.080 \pm 0.005$ & $56 \pm 2$ & $0.14 \pm 0.02$ & $46 \pm 5$ & $6.2 \pm 0.7$ \\
DC20 & $700 \pm 60$ & $0.082 \pm 0.003$ & $38 \pm 2$ & $0.18 \pm 0.03$ & $29 \pm 1$ & $5.6 \pm 1.0$ \\
DC25 & $510 \pm 20$ & $0.081 \pm 0.002$ & $30 \pm 1$ & $0.20 \pm 0.04$ & $22 \pm 1$ & $4.5 \pm 0.9$ \\
DC30 & $380 \pm 30$ & $0.088 \pm 0.008$ & $23 \pm 1$ & $0.4 \pm 0.2$ & $17 \pm 1$ & $8 \pm 3$ \\
\hline
\end{tabular}




\section{REFERENCES}

S1. Banyay, M.; Sarkar, M,; Gräslund A. A Library of IR of Nucleic Acids in Solution, Biophys. Chem. 2003, 104, 477-488.

S2. Tanzi, L.; Benassi, P.; Nardone, M.; Ramondo, F. Vibrations of Bioionic Liquids by Ab Initio Molecular Dynamics and Vibrational Spectroscopy, J. Phys. Chem. A 2014, 118, 12229-12240.

S3. Vieira, L.; Schennach, R.; Gollas, B. In situ PM-IRRAS of a Glassy Carbon Electrode/deep Eutectic Solvent Interface, Phys. Chem. Chem. Phys. 2015, 17, 12870-12880.

S4. Nakano, M.; Tateishi-Karimata, H.; Tanaka, S.; Sugimoto, N. Choline Ion Interactions with DNA Atoms Explain Unique Stabilization of A-T Base Pairs in DNA Duplexes: A Microscopic View. J. Phys. Chem. B 2014, 118, 379-389.

S5. Marušič, M.; Tateishi-Karimata, H.; Sugimoto, N.; Plavec, J. Structural Foundation for DNA Behavior in Hydrated Ionic Liquid: An NMR Study. Biochimie 2015, 108, 169-177.

S6. Matsuno, H.; Nakahara, J.; Tanaka, K. Dynamic Mechanical Properties of Solid Films of Deoxyribonucleic Acid, Biomacromolecules 2011, 12, 173-178. 